\title{
Magnesium Status After Gastric Bypass Surgery
}

\author{
Arvo Haenni
}

Published online: 6 April 2011

(C) Springer Science+Business Media, LLC 2011

\section{Dear Editor,}

Regarding the interesting paper "Long-Term Nutritional Outcome After Gastric Bypass" by Lorenca Dalcanale et al., published in Obesity Surgery 2010; 20:181-7, we have questions about the prevalence of magnesium deficiency in subjects treated with gastric bypass surgery. The authors report that $32.1 \%$ of the patients treated with gastric bypass are magnesium deficient. However, the authors do not show how many of the subjects were magnesium deficient at baseline, i.e., at the preoperative state. The mean value for circulating magnesium concentration was $1.5 \pm 0.2 \mathrm{mg} / \mathrm{dL}$ at baseline (Table 2 in the paper), which might imply that some subjects were magnesium deficient also in the preoperative state since the reference value for magnesium is $>1.6 \mathrm{mg} / \mathrm{dL}$ in the present study. In Table 2, the authors show a preoperative circulating magnesium concentration of $1.5 \pm 0.2 \mathrm{mg} / \mathrm{dL}$ and a 2 -year value of $1.7 \pm 0.1 \mathrm{mg} / \mathrm{dL}$ and a current value of $1.7 \pm 0.5 \mathrm{mg} / \mathrm{dL}$ which seems to indicate an increased magnesium concentration rather than a decrease.

Furthermore, in the discussion, the authors make the statement that "the hypomagnesemia by $34 \%$, consistent with present findings, was already registered years ago", referring to Brolin RE, Leung M, Obes Surg 1999; 9:150-4. However, in that paper, nothing is mentioned about magnesium deficiency; in fact, magnesium is not mentioned at all.

It would be of great value if the authors could explain (1) How did the prevalence of magnesium deficiency change from baseline to the follow-up visits? and (2) What information in the paper by Brolin and Leung, ref. 15, supports the magnesium findings in your paper?

Best regards.

\section{Conflicts of Interest None.}

\footnotetext{
A. Haenni $(\bowtie)$

Department of Clinical Trials/Obesity Unit and Department of Public Health and Caring Sciences, University Hospital and Uppsala University,

P O Box 609, SE-751 25, Uppsala, Sweden

e-mail: arvo.hanni@pubcare.uu.se
} 